\title{
Inhibitory effects of epigallocatechin gallate on compound 48/80-induced mast cell activation and passive cutaneous anaphylaxis
}

\author{
Guang Zhao $\mathrm{Li}^{1,2}$, Ok Hee Chai ${ }^{1}$ \\ and Chang Ho Song ${ }^{1,3}$ \\ 1 Department of Anatomy and \\ Research Center for Allergic Immune Diseases \\ Chonbuk National University Medical School \\ Jeonju, Jeonbuk 561-756, Korea \\ ${ }^{2}$ Department of Anatomy \\ Yanbian University Medical School \\ Juzi Street 121, Yanji City, 133000, China \\ ${ }^{3}$ Corresponding author: Tel, 82-63-270-3101; \\ Fax, 82-63-274-9880; E-mail, asch@chonbuk.ac.kr
}

Accepted 1 July 2005

Abbreviation: C48/80, compound 48/80; EC, epicatechin; ECG, epicatechin gallate, EGC, epigallocatechin; EGCG, epigallocatechin gallate; PCA, passive cutaneous anaphylaxis; RPMC, rat peritoneal mast cells

\begin{abstract}
Epigallocatechin gallate (EGCG) is a principle phenolic antioxidant found in a variety of plants, including green and black tea. The anti-allergic effect of EGCG is unknown. The purpose of this study is to investigate the effects of EGCG on compound 48/80-induced mast cell activation and passive cutaneous anaphylaxis. For this, the influences of EGCG on the compound 48/80-induced cutaneous reaction were measured in vivo and the effects of EGCG on the compound 48/80-induced mast cell activations were examined in vitro. Results are below: as 1) EGCG significantly inhibited compound 48/80-induced passive cutaneous anaphylaxis, 2) the compound 48/80-induced degranulation, calcium influx and histamine release of rat peritoneal mast cells (RPMCs) were significantly inhibited by the pretreatment with EGCG, and 3) the compound 48/80-mediated inhibition of cAMP level in RPMCs was significantly increased by the pretreatment with EGCG. These results suggested that EGCG, the most abundant polyphenol in green tea, inhibits the compound 48/80-induced mast cell activation and the increase of vascular permeability, and potentially serve as effective
\end{abstract}

therapeutic tools for allergic diseases.

Keywords: calcium signaling; cell degranulation; cyclic AMP; epigallocatechin gallate; histamine; mast cell

\section{Introduction}

Mast cells are known to play a crucial role in the development of many physiological changes during an immediate allergic response (Lantz et al, 1998). Activation of mast cells, the key cells of allergic inflammatory reactions, occurs in response to a challenge by a specific antigen against which the surface $\lg \mathrm{E}$ is directed, or by other IgE-directed ligands. In IgE-mediated activation, a variety of biological substances (products of complement activation, neuropeptides and certain cytokines), pharmacological compounds (calcium ionophore, compound 48/80, and mellitin), and physical stimuli can elicit the release of mast cell mediators (Chai et al., 2000, 2001; Platts-Mills, 2001). These mediators ultimately cause the various symptoms of allergy including dermatitis and asthma.

Green tea, derived from the plant Camellia sinesis (an evergreen shrub of the theaceae family), is one of the most popularly consumed beverages in the world. Green tea, specially green tea catechins, shows the pharmacological effects such as anticarcinogenic activity (Ogata et al., 1995; Stoner and Mukhtar, 1995), antioxidant activity (Han, 2003; Kim et al., 2004), anticarcinogenic and related dental activity (Hattori et al., 1990; Saeki et al., 1993), antimicrobial activity (Ikigai et al., 1993), and prevention of cardiovascular disease (Uchida et al., 1995; Yokozawa et al., 1995). Most of the polyphenols in green tea are flavanols, commonly known as catechins: the major catechins in green tea are (-)-epicatechin (EC), (-)-epicatechin-3-gallate (ECG), (-)-epigallocatechin (EGC), and (-)-epigallocatechin-3-gallate (EGCG) (Ahmad et al., 1998).

EGCG, the most abundant polyphenol in green tea, is known to induce apoptosis and cell cycle arrest in tumor cells (Ahmad et al., 1997). Other studies showed that this compound inhibits urokinase activity (Jankun et al., 1997), cell proliferation (Asano et al., 1997), mitogen-activated protein kinase activation (Ahn et al., 1999), and lipoxygenase and cyclooxygenase activities (Stoner an Mukhtar, 1995). ECG, 
$E G C$, and EGCG have recently shown to inhibit antigen- or a calcium ionophore A23187-induced histamine release from RBL-2H3 (Matsuo et al., 1996; 1997). However, the mechanism of the inhibition is poorly understood. Since mast cells are activated to release chemical mediators, and calcium and cAMP are shown to play a pivotal role in the mast cell activations, we assessed the effect of ECGC on the calcium uptake and change of intracellular cAMP in mast cells. In this paper we show that EGCG inhibits the compound 48/80-induced mast cell activations and the increased vascular permeability while cAMP level is increased.

\section{Materials and Methods}

\section{Materials}

Compound 48/80, bovine serum albumin (BSA), Evans blue, and trypan blue were purchased from Sigma Chemical Co. (St. Louis, MO). Percoll solution was purchased from Pharmacia (Uppsala, Sweden). EGCG were purchased from Cyman Chemical (Ann Arbor, MI). ${ }^{14} \mathrm{C},{ }^{45} \mathrm{Ca}$ and cAMP kit were purchased from Perkin Elmer Life Science Inc. (Boston, MA). Male Sprague-Dawley rats aged 10 weeks purchased from Korean Damool Science (Taejeon, Chungnam, Korea). They were housed the experiments in a laminar flow cabinet and article lighting conditions with 12-hr d/night cycle and had access to food and water ad libitum.

\section{Passive cutaneous anaphylaxis (PCA)}

Evans blue dye was prepared as a $0.5 \%$ solution $(w / v)$ in sterilized saline. Test compounds were prepared in saline. Male Sprague-Dawley rats were light anesthetized with ether, back skin hair was shaved, and rats were injected intradermally with 50 $\mu l$ per site of the various concentrations of EGCG. After $10 \mathrm{~min}$, rats were injected intradermally with 250 ng per site of compound 48/80. As a control, the dorsal skin site of these rats was injected with saline alone. Thirty min after the intravenous injection of Evans blue, all rats were sacrificed and the dorsal skin was removed to measure the pigment area. The amount of dye in the tissue was then determined colorimetrically after extraction with $1 \mathrm{ml}$ of formamide, according to the method outlined by Fleming et al. (1997). The absorbent intensity of the extraction was measured at $620 \mathrm{~nm}$ in a spectrofluorometer (Spectra MAX PLUS, Molecular Devices, Sunnyvale, $\mathrm{CA}$ ), and the amount of dye was calculated with the Evans blue standard curve.

\section{Preparation of rat peritoneal mast cells (RPMCs) suspension and microscopic observation}

RPMCs were isolated as previously described (Cochrane and Douglas, 1974). In brief, rats were anesthetized with ether and injected with $10 \mathrm{ml}$ of calcium-free HEPES-Tyrode buffer (136 mM NaCl, 5 $\mathrm{mM} \mathrm{KCl}, 11 \mathrm{mM} \mathrm{NaHCO}, 0.6 \mathrm{mM} \mathrm{NaH} \mathrm{PO}_{4}, 2.75$ $\mathrm{mM} \mathrm{MgCl}$, $5.4 \mathrm{mM}$ HEPES, $1.0 \mathrm{mg} / \mathrm{ml}$ bovine serum albumin, $1.0 \mathrm{mg} / \mathrm{ml}$ glucose, $0.1 \mathrm{mg} / \mathrm{ml}$ heparin) into the peritoneal cavity, and the abdomen was gently massaged for $90 \mathrm{~s}$. The peritoneal cavity was opened, and the fluid was aspirated using a Pasteur pipette, and RPMCs were purified by a percoll density gradient as described in detail elsewhere (Hachisuka et al., 1988). Purified mast cells $\left(1 \times 10^{6} \mathrm{cells} / \mathrm{ml}\right)$ were resuspended in HEPES-Tyrode buffer. Mast cells were observed under phase contrast and photographed as described. RPMCs preparations were at least $95 \%$ pure and at least $98 \%$ of these cells were viable as assessed by trypan blue exclusion (Mascotti et al., 2000).

\section{Assay of histamine release}

Mast cell suspensions $(200 \mu \mathrm{l})$ were preincubated with the various concentrations of EGCG $(25 \mu \mathrm{l})$ for $10 \mathrm{~min}$ at $37^{\circ} \mathrm{C}$ and then incubated with compound $48 / 80$ (250 $\mathrm{ng}$ in $25 \mu \mathrm{l}$ ). The reaction was stopped by cooling the tubes in ice bath. The released histamine were separated from the cells by centrifugation at $150 \mathrm{~g}$ for $10 \mathrm{~min}$ at $4^{\circ} \mathrm{C}$. Histamine present in the cells was released by disrupting the cells with boiling and centrifugation. Histamine content was measured by the radioenzymatic method described by Harvima et al., (1988). The inhibition percentage of the histamine release was calculated using the following formula: $\%$ Inhibition $=[($ Histamine release without EGCG - Histamine release with EGCG) / Histamine release without EGCG] $\times 100$.

\section{Measurement of ${ }^{45} \mathrm{Ca}$ uptake}

The calcium uptake of mast cells was measured according to the method described by Chai et al., (2001). Mast cells were suspended in HEPES-Tyrode buffer containing ${ }^{45} \mathrm{Ca}\left(1.5 \mathrm{MCi} / \mathrm{ml} ; 1 \mathrm{Ci}=3.7 \times 10^{10}\right.$ becquerels), and incubated for $10 \mathrm{~min}$ at $4^{\circ} \mathrm{C}$. Mast cell suspensions $(200 \mu \mathrm{l})$ were incubated with the various concentrations of EGCG $(25 \mu \mathrm{l})$ for $10 \mathrm{~min}$ at $37^{\circ} \mathrm{C}$ and then with compound 48/80 (250 ng in $25 \mu \mathrm{l}$ ) for $20 \mathrm{~min}$. The reaction was stopped by the addition of $1 \mathrm{mM}$ lanthanuim chloride and washed 3 times with HEPES-Tyrode buffer at $4^{\circ} \mathrm{C}$ for $10 \mathrm{~min}$. The cells were disrupted with $10 \%$ Triton $\mathrm{X}-100$ by vigorous shaking. Radioactivity in the solution was measured in a scintillation $\beta$-counter. 


\section{Measurement of cyclic adenosine-3',5' monophos - phate (cAMP) level}

The cAMP level was measured according to Holmegaard's method (1982). In brief, mast cell suspensions were added to an equivalent vol $(200 \mu \mathrm{l})$ of prewarmed buffer containing the drug in an Eppendorf tube. The reaction was allowed to proceed for discrete time intervals, terminated by centrifugation, and then added $250 \mu \mathrm{l}$ of $50 \mathrm{mM}$ sodium acetate buffer $(\mathrm{pH}$ 6.2) under vigous vortexing, followed by snap frozen in liquid nitrogen. The frozen samples were thawed and vortexed, the debris was sedimented in a centrifuge $\left(400 \mathrm{~g}\right.$ at $4^{\circ} \mathrm{C}$, for $10 \mathrm{~min}$.). The cAMP level in the supernatant was determined by radioimmunoassay using a Rianen assay system (Boston, MA).

\section{Statistical analysis}

The data were expressed as mean \pm SEM. Student's $t$-test was used to make a statistical comparison between the groups. Results with $P<0.05$ were considered statistically significant.

\section{Results}

To assess the contribution of EGCG in passive cutaneous anaphylaxis, we first used the in vivo model of PCA. The PCA was best visualized by the extravasation of dye. As shown in Figure 1, compound $48 / 80$ induced the extravasation of Evans blue. However the intradermal administration of EGCG resulted in the inhibition of PCA reactions in a dosedependent manner, especially $50 \mu \mathrm{M}$ EGCG showed

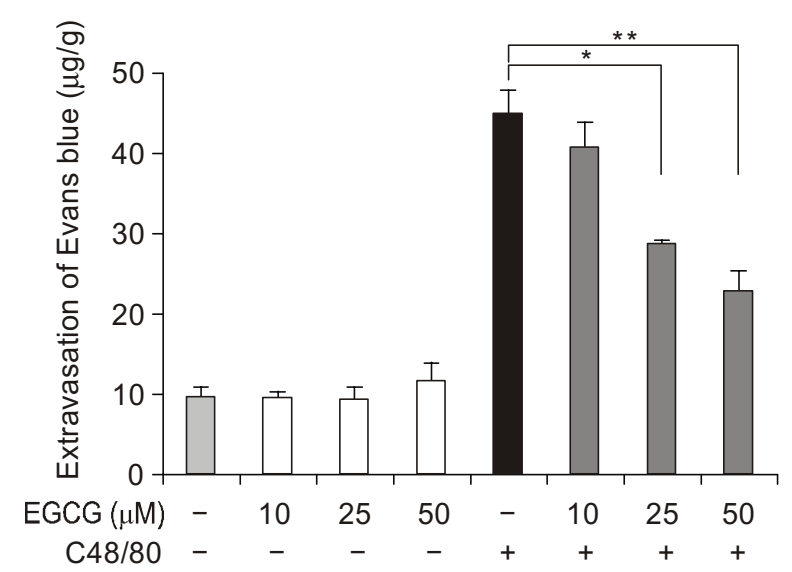

Figure 1. Inhibitory effect of Epigallocatechin Gallate (EGCG) on the compound 48/80 (C48/80)-induced passive cutaneous anaphylaxis. ${ }^{*} P<0.05,{ }^{*} P<0.01$. the marked inhibition on compound 48/80-induced extravasation of Evans blue (Figure 1). In addition, trypan blue exclusion test revealed that the EGCG ranging from $10 \mu \mathrm{M}$ to $50 \mu \mathrm{M}$ had no cytotoxicity on RPMCs (Figure 2).

To investigate the inhibitory mechanism of EGCG on anaphylactic reactions, we examined compound 48/ 80 -induced mast cell activation. First of all, inhibitory effects of EGCG on compound 48/80-induced mast cell degranulation were examined. Inverted microscopy technique showed that control RPMCs were generally spherical, or oval, and that had many fine granules surrounding a prominent nucleus (Figure $3 A)$. The spherical shape is $93.8 \%$ of population, the degranulation rate of control RPMCs was $6.2 \%$. After stimulation with compound $48 / 80$, the cell became swollen and had many vacuoles and extruded granules near the cell surface and in the surrounding medium, which is interpreted as mast cell degranulation (Figure 3B). The degranulation rate of compound $48 / 80$-treated RPMCs was $92 \%$. When RPMCs were incubated with EGCG, RPMCs were showed similar to that seen with the control RPMCs (Figure 3C). The degranulation rate of RPMCs by EGCG was $6.5 \%$. After the stimulation of EGCG-preincubated RPMCs with compound 48/80, the cells became swollen with an irregular boundary, but were not degranulated (Figure 3D). The degranulation rates of RPMCs treated with EGCG plus compound $48 / 80$ was $7.2 \%$. At $25 \mu \mathrm{M}$ of EGCG, the inhibition rate of degranulation rate was $95 \%$. Inhibitory effects of EGCG on compound 48/80-induced histamine release from RPMCs were also examined (Figure 4). Compound 48/80 induced the histamine release from RPMCs. EGCG alone had no effect on the spontan-

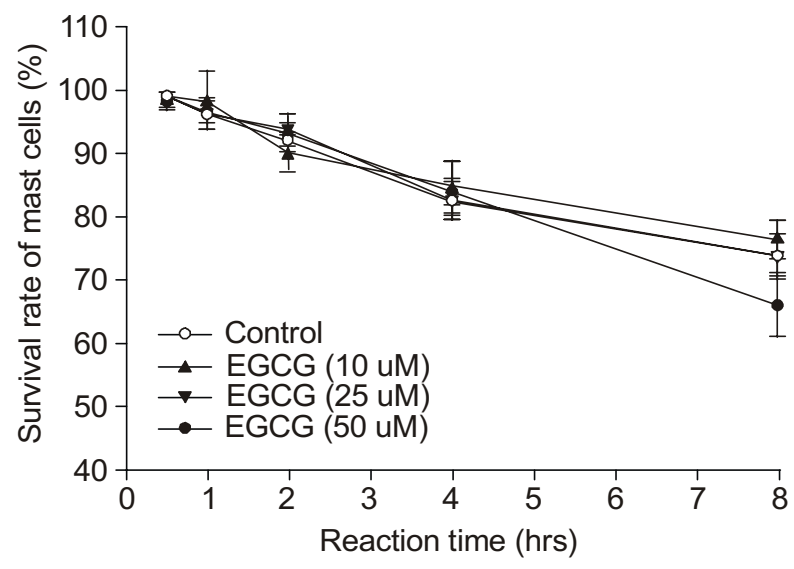

Figure 2. The cytotoxicity of Epigallocatechin Gallate (EGCG) in rat peritoneal mast cells by using trypan blue test. There were no significant differences in the survival rate of mast cells among all experimental groups. 

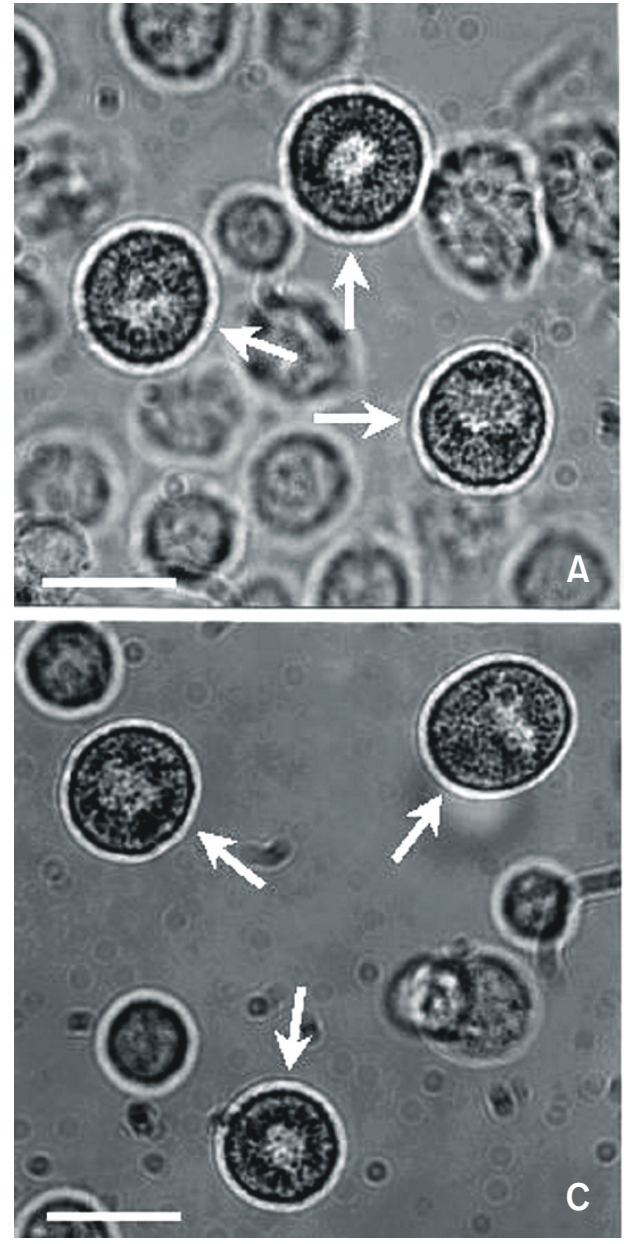

C
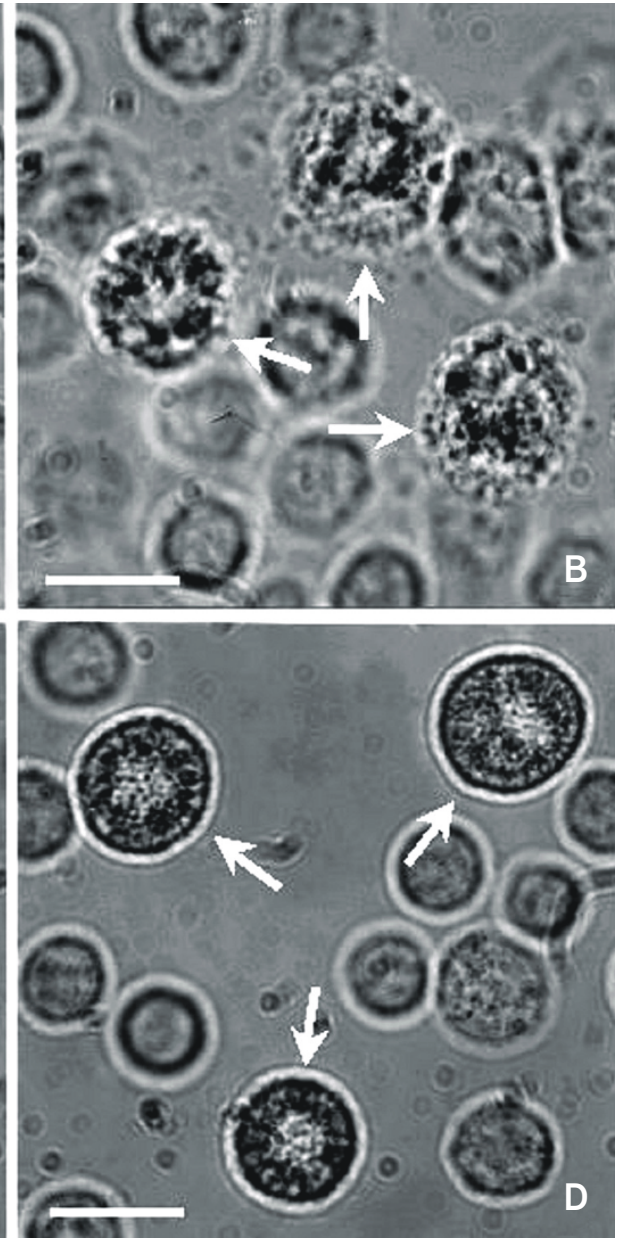

Figure 3. Light microphotographs using inverted microscopy of rat peritoneal mast cells (RPMCs) in HEPES-Tyrode buffer (A), after stimulation with $10 \mu \mathrm{g} / \mathrm{ml} \mathrm{com-}$ pound 48/80 (B), $10 \mu \mathrm{M}$ Epigallocatechin Gallate (EGCG) (C), and after being pretreated with $10 \mu \mathrm{M}$ EGCG prior to the stimulation with $10 \mu \mathrm{g} / \mathrm{ml}$ compound 48/80 (D). Normal RPMCs are generally characterized by round shape with fine granules and regular surface. Degranulated mast cells become swollen and have many vacuoles, an irregular surface and extruded granules. However, compound 48/80 did not induce degranulation of RPMCs pretreated with EGCG. Bar $=10 \mu \mathrm{M}$.

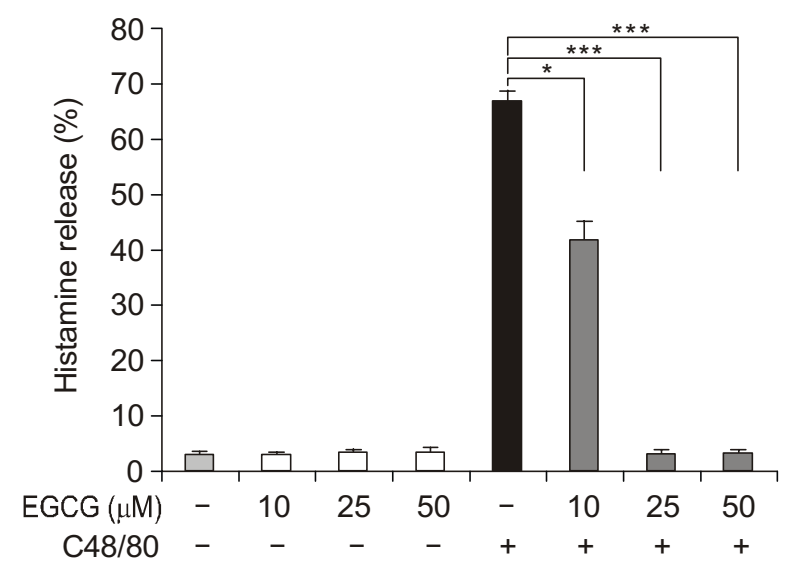

Figure 4. Inhibitory effect of Epigallocatechin Gallate (EGCG) on the compound $48 / 80$ (C48/80)-induced histamine release from rat peritoneal mast cells. ${ }^{*} P<0.05,{ }^{* * *} P<0.001$.

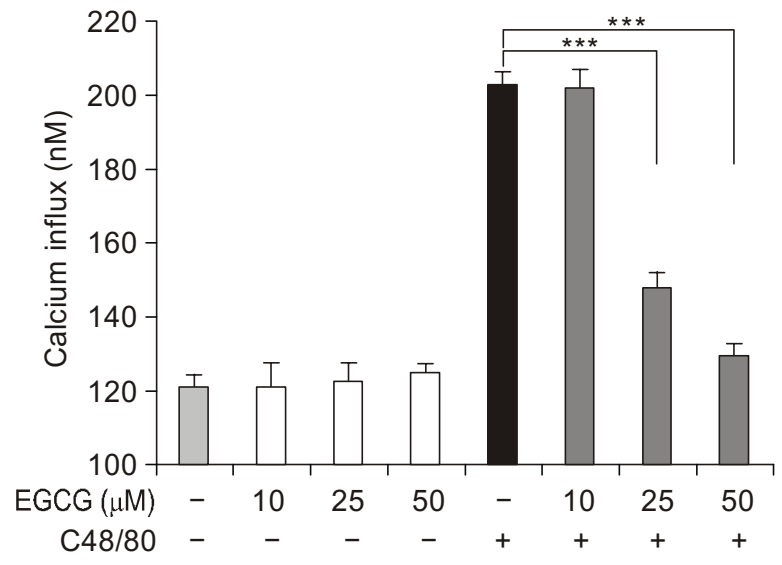

Figure 5. Inhibitory effect of Epigallocatechin Gallate (EGCG) on the compound $48 / 80$ (C48/80)-induced calcium uptake into the rat peritoneal mast cells. ${ }^{* *} P<0.001$. 


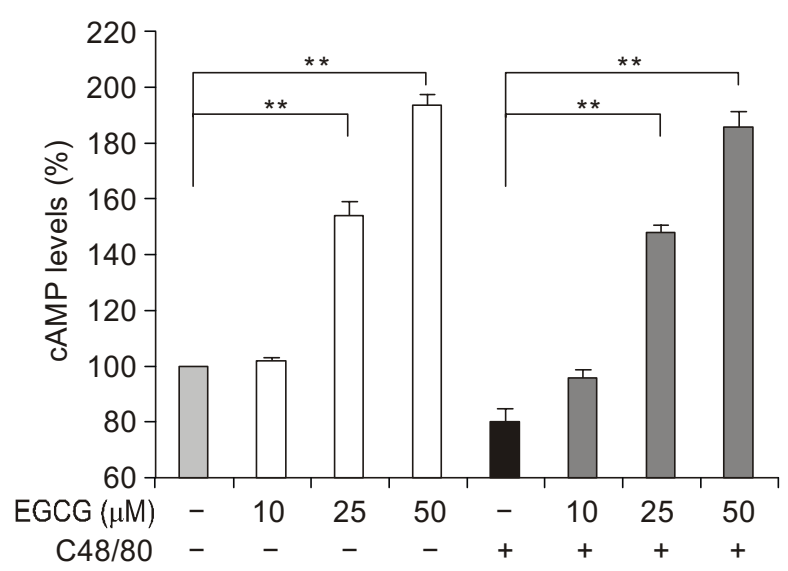

Figure 6. Inhibitory effect of Epigallocatechin Gallate (EGCG) on the compound $48 / 80$ (C48/80)-induced decrease of cAMP levels in the rat peritoneal mast cells. ${ }^{* *} P<0.01$

eous histamine release. However, EGCG dose-dependently inhibited the compound 48/80-induced histamine release (Figure 4). The histamine release was reduced by $40 \%$ at $10 \mu \mathrm{M}$ and $100 \%$ at $50 \mu \mathrm{M}$ EGCG from RPMCs. These results indicated that EGCG significantly inhibits the compound 48/80-induced PCA via inhibiting the compound 48/80-induced mast cell degranulation and histamine release from RPMCs.

The close correlations among the concentration of the histamine-releasing stimulus, calcium ion influx, and the amount of released histamine suggest a cause- and effect-relationship between the influx of calcium and release of histamine. And the release of histamine is depressed by an increase in the intracellular cAMP. So, we next examined the effect of EGCG on second messenger such as calcium and cAMP. EGCG alone did not affect the calcium uptake into RPMCs, and compound 48/80 induced the calcium uptake into the RPMCs. However, EGCG inhibited the compound 48/80-induced calcium uptake into RPMCs in a concentration-dependent manner (Figure $5)$. The calcium uptake into RPMCs was inhibited significantly at $25 \mu \mathrm{M}$ EGCG and almost completely inhibited by the administration of $50 \mu \mathrm{M}$ EGCG.

EGCG itself increased the cAMP level in RPMCs, 50 $\mu M$ EGCG increased more 2-fold increase in the cAMP level than those in control cells. RPMCs treated with compound $48 / 80$ caused less than 2 -fold decrease in the cAMP level as compared to those treated with buffer only. But EGCG inhibited the compound 48/80-induced cAMP reduction of RPMCs (Figure 6). These results suggest that EGCG contains an activity to inhibit the compound 48/80-induced mast cell activations and vascular permeability, via blocking of calcium uptake into RPMCs, or increasing of cAMP level in RPMCs.

\section{Discussion}

Green tea is the unprocessed dried young leaves of Camellia sinesis, also known as Thea sinensis L, which is widely consumed beverage in the world. Polyphenolic compounds such as catechins are ubiquitously found in green tea (Graham, 1992). The main polyphenolic compounds found in green tea are EC, ECG, EGC, and EGCG (Ahmad et al., 1998). These polyphenolic compounds exhibit protective effects against bacterial infection, tumor promotion and progression (Gao et al., 1994; Aucamp et al., 1997). ECG, EGC, EGCG are recently shown to inhibit the antigen- or calcium-ionophore A23187induced histamine release from RBL-2H3 (Matsuo et al., 1996; 1997).

We examined the effect of EGCG on PCA induced by compound $48 / 80$. Compound $48 / 80$ induced extravasation of Evans blue. However intradermal administration of EGCG resulted in the inhibition of PCA reactions in a dose-dependent manner, especially 50 $\mu M$ EGCG showed a marked inhibition on the compound 48/80-induced extravasation of Evans blue. In addition, Trypan blue exclusion test revealed that the EGCG ranging from $10 \mu \mathrm{M}$ to $50 \mu \mathrm{M}$ had no cytotoxicity on RPMCs.

To investigate the inhibitory mechanism of EGCG on PCA, we next examined the compound 48/80-induced mast cell activation. After the stimulation with compound $48 / 80$, the cell became swollen and exhibited many vacuoles and extruded granules near the cell surface and in the surrounding medium. Compound 48/80 induced mast cell degranulation and histamine release from RPMCs. it is well known that the stimulation of mast cells with compound 48/80 initiates the activation of a signal-transduction pathway, which leads to histamine release (Mousli et al., 1990). Compound $48 / 80$ stimulates the activity of protein tyrosine kinases, leading to the enhanced tyrosine phosphorylation of a number of cellular proteins and to the activation of both the p42 and p44 mitogenactivated protein kinase. Activation of the protein tyrosine kinases pathway occurred via a mechanism that involves protein kinase, phosphatidylinositol 3kinase, and $\mathrm{Ca}^{2+}$ as intermediates (Shefler and SagiEisenberg, 2001). Thus, application of compound $48 / 80$ and other cationic secretagogues transiently increase intracellular $\mathrm{Ca}^{2+}$ concentrations through $\mathrm{G}$ protein-mediated activation of phospholipase $\mathrm{C}$. The calcium influx has two main results (Daniele, 1989). Firstly, there is an exocytosis of granule content with the release of preformed mediators, the major one being histamine. Secondly, there is the induction of synthesis of newly formed mediators from arachidonic acid leading to the production of prostaglandins and leukotrienes. EGCG alone had no effect on the mast 
cell degranulation and the spontaneous histamine release. However, EGCG dose-dependently inhibited the compound 48/80-induced mast cell degranulation and the histamine release from RPMCs.

The close correlations among the concentration of the histamine-releasing stimulus, calcium ion influx (Raison et al., 1999), and the amount of released histamine suggest a cause- and effect-relationship between the influx of calcium and release of histamine (Hachisuka et al., 1988; Daniele, 1989; Lorenz et al., 1998). And the release of histamine is depressed by an increase in the intracellular cAMP (Makino et al., 1987; Alfonso et al., 2000; Sarkar et al., 2003). So, we examined the effect of EGCG on second messenger such as calcium and cAMP. EGCG alone did not affect the calcium uptake into RPMCs, and compound 48/80 induced the calcium uptake into RPMCs. However, EGCG inhibited the compound 48/80-induced calcium uptake into RPMCs in a concentration-dependent manner. EGCG itself increased the cAMP level in RPMCs, $50 \mu \mathrm{M}$ EGCG increased more 2-fold increase in the cAMP level than those in control cells. RPMCs treated with compound 48/80 caused less than 2-fold decrease in the cAMP level as compared to these treated with buffer only. But EGCG inhibited the compound $48 / 80$-induced cAMP reduction of RPMCs. The release of histamine is depressed by an increase in the intracellular CAMP content due to the activation of adenylate cyclase or inhibitor of cAMP phosphodiesterase (Makino et al., 1987; Alfonso et al., 2000; Sarkar et al., 2003). The inhibitory effect of EGCG on mast cell degranulation and histamine release from mast cells may be related to the prevention of an increase of intracellular calcium content owing to elevation of the intracellular cAMP level by increase of adenylate cyclase activity or inhibition of the cAMP phosphodiesterase.

Drinking green tea daily would contribute to maintaining plasma catechin levels sufficient to exert antioxidant and anti-allergic activity in blood circulation system (Nakagawa et al., 1997). Kang and colleagues reported that $121.3 \mathrm{mg}$ of EGCG was obtained from $5 \mathrm{~g}$ of dry green tea by extracting in $50^{\circ} \mathrm{C}$ water (Kang et al., 1999). Also, Japanese epidemiologists reported that one cup of green tea infusion contained 100-200 mg of polyphenolic compounds (Kono et al., 1988). Therefore, the suggested daily dosage of polyphenols is 240 to $320 \mathrm{mg}$, equal to about 3 cups of green tea.

In conclusion, we show that EGCG can inhibit the histamine release from RPMCs mainly by inhibiting calcium uptake and increasing of cAMP level, a critical event in the signal transduction leading to secretion. These findings suggest that EGCG, the most abundant polyphenol in green tea, potentially serve as effective therapeutic tools for allergic diseases.

\section{Acknowledgment}

This study was supported by a grant of the Korea Health 21 R\&D Project, Ministry of Health \& Welfare, Republic of Korea (02-PJ1-PG1-CH01-0006).

\section{References}

Ahmad N, Feyes DK, Nieminen AL, Agarwal R, Mukhtar H. Green tea constituent epigallocatechin-3-gallate and induction of apoptosis and cell cycle arrest in human carcinoma cells. J Natl Cancer Inst 1997;89:1881-6

Ahmad N, Katiyar SK, Mukhtar H. Cancer chemoprevention by tea polyphenols. In Nutrition and Chemical Toxicity (loannides C, eds), 1998, p301, West Sussex, England

Ahn HY, Hadizadeh KR, Seul C, Yun YP, Vetter H, Sachinidis A. Epigallocathechin-3 gallate selectively inhibits the PDGFBB-induced intracellular signaling transduction pathway in vascular smooth muscle cells and inhibits transformation of sis-transfected NIH 3T3 fibroblasts and human glioblastoma cells (A172). Mol Biol Cell 1999;10:1093-104

Alfonso A, Cabado AG, Vieytes MR, Botana LM. Functional compartments in rat mast cells for cAMP and calcium on histamine release. Cell Signal 2000;12:343-50

Asano Y, Okamura S, Ogo T, Eto T, Otsuka T, Niho Y. Effect of (-)-epogallocatechin gallate on leukemic blast cells from patients with acute myeloblast leukemia. Life Sci 1997;60: $135-42$

Aucamp J, Gaspar A, Hara Y, Apostolides Z. Inhibition of xanthine oxidase by catechins from tea (Camellia sinensis). Anticancer Res 1997;17:4381-5

Chai $\mathrm{OH}$, Lee $\mathrm{YH}$, Han $\mathrm{EH}$, Kim HT, Lee MS, Song $\mathrm{CH}$. Atrial natriuretic peptide induces rat peritoneal mast cell activation by cGMP-independent and calcium-dependent mechanism. Exp Mol Med 2000;32:179-86

Chai OH, Kim EK, Lee YH, Kim JG, Baik BJ, Lee MS, Han $\mathrm{EH}$, Kim HT, Song $\mathrm{CH}$. Histamine release induced by dendroaspis natriuretic peptide from rat mast cells. Peptides 2001;22:1421-6

Cochrane DE, Douglas WW. Calcium-induced extrusion of secretory granules (exocytosis) in mast cells exposed to $48 / 80$ or the ionophores A23187 and X-537A. Proc Natl Acad Sci USA 1974;71:408-12

Daniele RP. Asthma. In Cecil textbook of medicine (Wyngaaden JB, Smith LH, eds), 1989, 403-10, W.B. Sauders company

Fleming TJ, Donnadieu E, Song CH, Laethem FV, Galli SJ, Kinet JP. Negative regulation of FC epsilon RI-mediated degranulation by CD81. J Exp Med 1997;186:1307-14

Gao YT, McLaughlin JK, Blot WJ, Ji BT, Dai Q, Fraumeni JFJr. Reduced risk of esophageal cancer associated with green tea consumption. J Natl Cancer Inst 1994;86:855-8 
Graham HN. Green tea composition, consumption, and polyphenol chemistry. Prev Med 1992;21:334-50

Hachisuka H, Nomura H, Sakamoto F, Mori O, Okubo K, Sasai $Y$. Effect of antianaphylactic agents on substance-P induced histamine release from rat peritoneal mast cells. Arch Dermatol Res 1988;280:158-62

Han MK. Epigallocatechin gallate, a constitieunt of green tea, suppresses cytokine-induced pancreatic $\beta$-cell damage. Exp Mol Med 2003;35:136-9

Harvima RJ, Harvima IT, Fraki JE. Optimization of histamine radio enzymatic assay with purified histamine-N-methyltransferase. Clin Chim Acta 1988;171:247-56

Hattori M, Kusumoto IT, Namba T, Ishigami T, Hara Y. Effect of tea polyphenols on glucan systhesis by glucosyltrasferase from Streptococcus mutans. Chem Pharm Bull (Tokyo) 1990;38: 717-20

Holmeggard SN. Measurement of cyclic AMP in clinical investigation. Acta Endocrinol Suppl (Copenh) 1982;249:1-47

Ikigai H, Nakae T, Hara Y, Shimamura T. Bactericidal catechins damage the lipid bilayer. Biochim Biophys Acta 1993;1147:132-6

Jankun J, Selman SH, Swiercz R, Skrzypczak-Jankun E. Why drinking green tea could prevent cancer. Nature 1997;387:561

Kang JH, Park YK, Chung ST, Row KH. Extraction and purification of EGCG (Epigallocatechin Gallate) from green tea. Korean J Biotechnol Bioeng 1999;14:517-22

Kim YS, Jhon DY, Lee KY. Involvement of ROS and JNK 1 in selenite-induced apoptosis in Chang liver cells. Exp Mol Med 2004;36:157-64

Kono S, Ikeda M, Tokudome S, Kuratsune M. A case-control study of gastric cancer and diet in Northern Kyusyu, Japan. Jpn J Cancer Res 1988;79:1067-74

Lantz CS, Boesiger J, Song CH, Mach N, Kobayashi T, Mulligan RC, Nawa Y, Dranoff G, Galli SJ. Role for interleukin-3 in mast-cell and basophil development and in immunity to parasites. Nature 1998;392:90-3

Lorenz D, Wiesner B, Zipper J, Winkler A, Krause E, Beyermann $M$, Lindau $M$, Bienert $M$. Mechanism of peptideinduced mast cell degranulation translocation and patchclamp studies. J Gen Physiol 1998;112:577-91

Makino H, Saijo T, Ashida Y, Kurici HH, Maki Y. Mechanism of action of an antiallergic agent, Amlexanox (AA-673), in inhibiting histamine release from mast cells. Int Arch Allergy Immunol 1987;82:66-71

Mascotti K, McCullough J, Burger SR. HPC viability measurement: trypan blue versus acridine orange and propidium iodide. Transfusion 2000;40:693-6
Matsuo N, Yamada K, Yamashita K, Shoji K, Mori M, Sugano $M$. Inhibitory effect of tea polyphenols on histamine and leukotriene B4 release from rat peritoneal exudate cells. In Vitro Cell Dev Biol Anim 1996;32:340-4

Matsuo N, Yamada K, Shoji K, Mori M, Sugano M. Effect of tea polyphenols on histamine release from rat basophilic leukemia (RBL-2H3) cells: the structure-inhibitory activity relationship. Allergy 1997;52:58-64

Mousli MC, Bronner C, Landy Y, Bockaert J, Rouot B. Direct activation of GTP-binding regulatory proteins ( $G$ proteins) by substance $P$ and compound 48/80. FEBS Lett 1990;259: 260-2

Nakagawa K, Okuda S, Miyazawa T. Dose-dependent incorporation of tea catechins, (-)-epigallocatechin-3-gallate and (-)-epigallocatechin, into human plasma. Biosci Biotechnol Biochem 1997;61:1981-5

Ogata K, Mukae N, Suzuki Y, Satoh K, Narumi K, Nukiwa T, Isemura M. Effects of catechins on the mouse tumor cell adhesion to fibronectin. Planta Med 1995;61:472-4

Platts-Mills, T. Hypersensitivity - Type I, In Immunology (Roitt I, Brostoff J, Male D, eds), 2001, 323-43, Mosby, New York

Raison S, Gillot I, Choine C, Pistone P, Pagnotta S, Laugier $J$ P, Nicaise G. Ca increase in secretory granules of stimulated mast cells. Cell Calcium 1999;26:111-9

Saeki $Y$, Ito $Y$, Shibata M, Sato $Y$, Takazoe I, Okuda K. Antimicrobial action of green tea extract, flavono flavor, copper chorophyll against oral bacteria. Bull Tokyo Dent Coll 1993;34:33-7

Sarkar A, Sreenivasan Y, Manna SK. alpha-Melanocytestimulating hormone induces cell death in mast cells: involvement of NF-kappaB. FEBS Lett 2003; 549:87-93

Shefler I, Sagi-Eisenberg R. Gi-mediated activation of the Syk kinase by the receptor mimetic base secretagogues of mast cells: Role in mediating arachidonic acid/metabolites release. J Immunol 2001;167:475-81

Stoner GD, Mukhtar H. Polyphenols as cancer chemopreventive agents. J Cell Biochem Suppl 1995;22:169-80

Uchida S, Ozaki M, Akashi T, Yamashita K, Niwa M, Taniyama K. Effects of (-)-epigallocatechin 3-O-gallate (green tea tannin) on the life span of strike-prone spontaneously hypertensive rats. Clin Exp Pharmacol Physiol 1995;22:302s-3s

Yokozawa T, Oura H, Nakagawa H, Sakanaka S, Kim M. Effects of component of green tea on the proliferation of vascular smooth cells. Biosci Biotechnol Biochem 1995; 59:2134-9 